ORIGINAL ARTICLE

\title{
PROGNOSTIC FACTORS OF ULTRASONOGRAPHY OF YOLK SAC SIZE AND EMBRYONIC HEART RATE IN FIRST TRIMESTER PREGNANCY OUTCOME
}

\author{
Lebda I, El-Fawal F, El-samak A and Abo Elwan H* \\ Radiology Department, Faculty of Medicine, Zagazig University, Zagazig, Egypt
}

\begin{abstract}
*Corresponding Author:
Heba Usef Abo Elwan

Radiology Department,

Faculty of Medicine, Zagazig

University, Zagazig, Egypt

Email:

dr.romance89@yahoo.com
\end{abstract}

$\begin{array}{ll}\text { Submit Date } & 2019-03-24 \\ \text { Revise Date } & 2019-04-14 \\ \text { Accept Date } & 2019-04-14\end{array}$

ABSTRACT
Background: Approximately $15-20 \%$ of the pregnancies are terminated by miscarriage. Yolk sac first appears at about 5 weeks gestation and is visualized by ultrasound and embryonic heart rate can be used as prognostic factors for first trimester pregnancy outcome. The aim of this study was to evaluate the yolk sac size and embryonic heart rate and to examine whether these parameters could serve as a prognostic factors for the first trimester pregnancy outcome. Methods: The study included 52 pregnant women in their first trimester from 6 weeks till 12 weeks gestation. Informed consent was taken from every patient. This study conducted at outpatient clinic of radiology department at maternity unit of Zagazig University Hospitals during the period from November 2016 till May 2017. Results: These cases allocated into 4 groups; according to gestational age The vast majority of YSD in the studied groups had normal sac diameter $(80.8 \%)$. There was a positive significant correlation between YSD and gestational age in miscarriage group (Group IV), while non significant correlation in other groups. EHR of miscarriage group IV was highly significant lower than that of other groups. EHR of miscarriage group IV was highly significant lower than that of other groups. Conclusion: Abnormal yolk sac diameter, in the form of small, enlarged, absent or irregular yolk sac, and embryonic bradycardia are associated with poor pregnancy outcome; independent of maternal risk factors such as age, body mass index or parity.

Keywords: Yolk sac; Embryonic heart rate (HER); First trimester outcome.

\section{INTRODUCTION}

\section{A} pproximately $15-20 \%$ of the pregnancies are terminated by miscarriage [1]. Yolk sac first appears at about 5 weeks gestation and is visualized by ultrasound as a prominent sonolucent center and echogenic rim, and increases in size up to 8 to 11 weeks gestation and then disappears by 12 weeks [2]. Previous studies have described the association between embryonic well-beings and the characteristics of gestational sac [3], yolk sac[4], [5], and embryonic heart beats [6].

Different studies have investigated the size, structure and function of the yolk sac [7] and [8]. The pregnancies with a yolk sac diameter $>5 \mathrm{~mm}$ had a significantly higher risk of miscarriage. Miscarriage occurred in $37.5 \%$ of pregnancies with enlarged yolk sacs and
$3.8 \%$ of pregnancies with irregular yolk sacs [9].

As pregnancy with normal yolk sac advances in the first trimester, the frequency of complications reduces. The sensitivity of predicting normal outcome with regular yolk sac is as high as $94.2 \%$ [10].

The embryonic heart beat can usually be identified, with improved visual resolution as early as 5 weeks. Both Doppler studies and motion moode (M-mode) are useful in this regard [11]. Fetal heart rate increased significantly from $118 \mathrm{BPM}$ to $167 \mathrm{BPM}$ between 6 and 10 weeks of gestation [12]. Studies suggested that a slow embryonic heart rate early in pregnancy (6-9 weeks of gestation) is associated with a high rate of subsequent fetal demise as embryonic heart 
rate $<100 \mathrm{BPM}$ is abnormal with miscarriage rate $83.3 \%$ [13].

The aim of this study was to evaluate the yolk sac size and embryonic heart rate and to examine whether these parameters could serve as prognostic factors for the first trimester pregnancy outcome.

\section{METHODS}

\section{Type of the study:}

This is a prospective cohort observational study.

Site:

Outpatient clinic of Radiology Department in Maternity Hospital of Zagazig University.

Time:

This study conducted during the period from November 2016 till May 2017.

\section{Ethical consideration:}

This study was approved from the college Institutional Review Board. Informed consent from each patient participate in this study was taken. The work was carried out in accordance with The Code of Ethics of the World Medical Association (Declaration of Helsinki) for studies involving humans.

Sample size:

The estimated sample size was 40 subjects (OPEN- EPI).

The study included 52 pregnant women in their first trimester from 6 weeks till 12 weeks gestation. These women fulfill the inclusion criteria, after complete counseling, and informed consent from each one participate in this study.

\section{Inclusion criteria:}

Pregnant women in their first trimester between 6-12 weeks, single gestational sac and positive heart motion seen in the embryo.

If the LMP not sure, early ultrasound examination using CRL was used to detect accurate gestational age.

\section{Exclusion criteria:}

Pregnant women with any problem during pregnancy e.g vaginal bleeding, abdominal cramps, pregnant patient with medical disorders that may be at a risk of miscarriage like diabetes, chronic hypertensive disorder, connective tissue disorders, patient with known uterine anomalies, patient refusing transvaginal sonography, patient do not like to continue the study; and unwilling for follw-up were excluded.

\section{Methods:}

The selected cases, informed oral and written consent were taken and subjected to the following procedures.

History taking: personal history, obstetric history , menstrual history, past history, history of present illness.

Clinical examination General examination including thyroid examination, and abdominal examination.

\section{Scanning technique:}

All pregnant women were assessed by Semins Axon x300 ultrasound machine with a 7.5 $\mathrm{MHz}$ vaginal probe, while the urinary bladder was empty.

A systematic approach was used during performing TVS.

The gestational sac and yolk sac were identified, the inner yolk sac diameter was measured by placing the calipers at inner margin.

A large yolk sac was defined as yolk sac with a diameter $\geq 5 \mathrm{~mm}$ and small with a diameter $<2 \mathrm{~mm}[9]$.

Embryonic heart rate were obtained transvaginally using M-mode sonography, after recording 6-10 heart beat cycles. The calculation of the heart rate was made by measuring the time interval of two cardiac cycles.

\section{Follow up of cases:}

All pregnancies were followed for their pregnancy outcome after completion of 12 weeks by either a subsequent ultrasound scan or a telephone interview.

The adverse outcome was spontaneous miscarriage occurring before or at 12 weeks of gestation.

\section{Statistical Analysis}

Data were entered checked and analyzed using Epi-SPSS version 20. Data were summarized using $\overline{\mathrm{X}} \pm \mathrm{SD}$ for quantitative 
variable frequency and percentage for categorical variables.

ANOVA, t-test and assessment of YSD, HER was done using ROC curve analysis. $\mathrm{P}<0.05$ was considered statistically significant.

\section{RESULTS}

A total of 52 pregnant women were recruited in the study from 6 weeks gestation, followed for their pregnancy outcome after completion of 12 weeks. These cases allocated into 4 groups; according to gestational age at presentation and second to pregnancy outcome.

Group (I) : women who were examined during (6-7weeks + 6days).

Group (II): women who were examined during (8-9 weeks +6days).

Group ( III): women who were examined during (10-12weeks).

Group (IV): women whose their pregnancies resulted into first trimester spontaneous miscarriage.

Our results showed that there were no statistical differences in the age, parity and BMI in the studied groups (Table 1). There was no statistical difference between all groups; except miscarriage group (Group IV) (Table 2). The vast majority of YSD in the studied groups had normal sac diameter $(86.5 \%)$ (Table 3, Fig 1s). All normal YSD continued beyond first trimester only one case of normal diameter end in miscarriage (Table 4).

There was a positive significant correlation between YSD and gestational age in miscarriage group (Group IV) while non significant correlation in other groups (Table 5). YSD had $97.6 \%$ sensitivity and $100 \%$ specificity in prediction of miscarriage with total accuracy of $98.1 \%$ (Table 6). EHR had a sensitivity of $97.5 \%$ \& specificity of $100 \%$ in the prediction of first trimester pregnancy outcome, with a total accuracy of $98.1 \%$ (Table 7).

When we studied the correlation of YSD with first trimester outcome, we found that all normal YSD continued beyond first trimester only one case of normal diameter end in miscarriage (Fig $2 \mathrm{~s}, \quad 3 \mathrm{~s}$ ).

Table (1): Demographic characteristic of the studied groups.

\begin{tabular}{|l|c|c|c|c|c|c|} 
& $\begin{array}{c}\text { Group I } \\
\mathbf{n}=\mathbf{2 3}\end{array}$ & $\begin{array}{c}\text { Group } \\
\text { II } \\
\mathbf{n = 1 1}\end{array}$ & $\begin{array}{c}\text { Group } \\
\text { III } \\
\mathbf{n = 7}\end{array}$ & $\begin{array}{c}\text { Group } \\
\text { IV } \\
\mathbf{n = 1 1}\end{array}$ & F & P \\
\hline $\begin{array}{c}\text { Age (years) } \\
\overline{\mathrm{X}} \pm \text { SD }\end{array}$ & $27.0 \pm 1.6$ & $27.9 \pm 2.3$ & $27.7 \pm 1.4$ & $26.7 \pm 1.5$ & 1.14 & 0.33 \\
\hline $\begin{array}{l}\text { Range } \\
\text { Parity }\end{array}$ & $25-30$ & $25-31$ & $25-30$ & $25-30$ & & \\
\hline $\bar{X} \pm$ SD & $2.2 \pm 0.7$ & $2.3 \pm .7$ & $1.9 \pm 0.7$ & $2.3 \pm 0.8$ & 0.7 & 0.53 \\
\hline Range & $1-3$ & $1-3$ & $1-3$ & $1-3$ & & \\
\hline BMI $\left(\mathrm{kg} / \mathrm{m}^{2}\right)$ & & & & & & 0.56 \\
\hline $\bar{X} \pm S D$ & $26.8 \pm 1.9$ & $26.5 \pm 1.9$ & $25.7 \pm 1.7$ & $26.3 \pm 1.7$ & 0.69 & \\
\hline Range & $24-29$ & $24-30$ & $24-29$ & $24-29$ & & \\
\hline
\end{tabular}

Table (2):Yolk sac diameter (YSD) in mm according to gestational age in weeks.

\begin{tabular}{|c|c|c|c|}
\hline Groups & $\mathbf{n}$ & $\begin{array}{c}\text { YSD } \\
\mathbf{X} \pm \text { SD (Range) }\end{array}$ & P \\
\hline I & 23 & $4.3 \pm 2.4(1.25-8.96)$ & \\
\hline II & 11 & $4.9 \pm 2.7(1.6-8.38)$ & $0.54(N S)$ \\
\hline III & 7 & $4.893 \pm 1.9(2.78-8.65)$ & $0.29(\mathrm{NS})$ \\
\hline IV & 11 & $2.0 \pm 0.4(1.7-2.53)$ & $0.005^{*}($ Sig. $)$ \\
\hline
\end{tabular}


Table (3): Distribution of yolk sac diameter (YSD) in the studied groups.

\begin{tabular}{|c|c|c|}
\hline YSD & Frequency & $\%$ \\
\hline Normal & 42 & 80.8 \\
\hline Irregular & 2 & 3.8 \\
\hline Abscent & 1 & 1.9 \\
\hline Enlarged & 4 & 7.7 \\
\hline Small & 3 & 5.8 \\
\hline Total & 52 & 100 \\
\hline
\end{tabular}

Table (4): Correlation of YSD with first trimester outcome.

\begin{tabular}{|c|c|c|c|c|}
\hline \multirow{2}{*}{ YSD } & & & Total & \multirow{2}{*}{ P-value } \\
\hline & Abortion & $\begin{array}{c}\text { Continued beyond } \\
12 \text { weeks }\end{array}$ & & \\
\hline Normal & 1 & 4 & 4 & \multirow[t]{5}{*}{$<0.001$} \\
\hline Enlarged & 4 & 0 & 4 & \\
\hline Irregular & 2 & 0 & 2 & \\
\hline Abscent & 1 & 0 & 1 & \\
\hline Small & 3 & 0 & 3 & \\
\hline Total & 11 & 4 & 52 & \\
\hline
\end{tabular}

Table (5): Correlation between gestational age (G.A) and YSD.

\begin{tabular}{|l|c|c|c|}
\hline & $\mathbf{R}$ & $\mathbf{P}$ & Sig. \\
\hline Group IV & 0.53 & $<0.05^{*}$ & Sig. \\
\hline Other & & & NSD \\
\hline GA \& YSD & 0.1 & $>0.05$ & \\
\hline
\end{tabular}

Table (6): Validity of YSD in prognosis of first trimester pregnancy outcome.

\begin{tabular}{|l|c|c|c|c|c|c|c|} 
& \multicolumn{2}{|c|}{ YSD } & Sensitivity & Specificity & PPV & NPV & Accuracy \\
\hline $\begin{array}{l}\text { Continue } \\
\text { preg. }\end{array}$ & 41 & 0 & $97.6 \%$ & $100 \%$ & $100 \%$ & 90.9 & $98.1 \%$ \\
\hline Miscarriage & 1 & 10 & & & & & \\
\hline
\end{tabular}

Table (7): Validity of embryonic heart rate (EHR) in prediction of first trimester pregnancy outcome.

\begin{tabular}{|l|c|c|c|c|c|c|c|}
\hline EHR*bpm) & & & Sensitivity & Specificity & PPV & NPV & Accuracy \\
\cline { 2 - 7 } & + ve & - ve & & & & & \\
\hline$>98$ & 39 & 0 & $97.5 \%$ & $100 \%$ & $100 \%$ & $92.3 \%$ & $98.1 \%$ \\
\hline$\leq 98$ & 1 & 12 & & & & & \\
\hline
\end{tabular}




\section{DISCUSSION}

The yolk sac (YS) is the first extra embryonic structure that becomes sonographically visible within the gestational sac and acts as the primary route of exchange between the human embryo and the mother before placental circulation is established. YS is normally visible by TVS by the end of the fifth week of pregnancy, increases gradually in diameter between the $5^{\text {th }}$ and $8^{\text {th }}$ weeks, grows slower until $11^{\text {th }}$ weeks and then decreases $[14,15]$.

Previous published data have demonstrated that; the lack of YS or a smaller than gestational age YS diameter are indicate of pregnancies that may result in spontaneous abortion [16]. Pregnancies with a very large YS are generally always associated with poor outcomes [7].

At 5-6 weeks GA, the mean embryonic heart rate is 101 (bpm). This rate increases to $143 \mathrm{bpm}$ by $8-9$ weeks and plateaus at approximately $140 \mathrm{bpm}$. It is not unusual for an initially detected embryonic heart rate (EHR) to be somewhat slower than the fetal heart rate recorded later in pregnancy. However, heart rate less than 85 bpm in embryos from 5+ to $8+$ weeks GA resulted in spontaneous miscarriage [17]. A continuous decline of EHR activity might inevitably be associated with miscarriage. Several previous [16] studies have associated severe embryonic bradycardia with subsequent fetal loss [18, 19].

This was a prospective cohort observesional study, carried out on 52 pregnant women in their first trimester from 6 weeks till 12 weeks gestational. A large YS was defined as YS with a diameter $\geq 5 \mathrm{~mm}$ and small with a diameter $<2 \mathrm{~mm}$. Embryonic heart rate (EHR) measurements were obtained transvaginally using M-mode sonography, after recording 6-10 heart beat cycles.

In the present study we find that enlarged YS (4 cases), irregular or absent YS (one case each) were highly significant associated with fetal loss. This suggests that measurement of the yolk sac diameter (YSD) was a reliable prognostic factor for the first trimester outcome.
The present study demonstrate the fact that visualization of YS is crucial for a normal pregnancy outcome. One case only out of 41 cases of normal YSD aborted $2.5 \%$. This in agreement with $\mathrm{Fu}$ et al [20], Chama et al [21] and Moradan and Forouzeshjfar [22].

In our study the YS was not visualized in one case $1.9 \%$ of cases; this is in agreement with Srivastava et al [23], who reported non visualization of YS in $0.67 \%$ cases. However, Xie and Chan [24] \& Mordan and Forouzeshjfar [22] find abscend YS in $4.5 \%$ and $4.3 \%$ in their cases. These finding is higher than our finding which may be explained by small sample size of our study. Thus, these studies strongly support the finding of the present study, that YS should always be present in normal pregnancies.

In the present study abnormal YSD (enlarged or small) was present in $13.4 \%$ of cases. This was approximately similar to finding of Shetty et al [26], Adija et al.,2015 [13] and Kucuk et al [27] which were $11.2 \%$, $10 \%$ and $11.4 \%$ respectively. Thus, these studies support that abnormal diameter of YS is strongly associated with miscarriage.

In the present study, non of the cases having enlarged YS continued beyond 12 weeks. This in agreement with the finding of Tan et al [9] who found $37.5 \%$ of their aborted cases had enlarged YS. According to Malinowski [28] and Cepni et al [15] visualization of a large size YS is a predictor of poor pregnancy outcome.

In the present study, small YS size was found in $5.7 \%$ of cases which was slightly higher $(3.7 \%)$ than found by Josel et al [29]. These findings support that small YSD is associated with adverse first trimester outcome and this fact is in agreement with Liao et al [30].

In this study abnormal (irregular) YS size was found in $5.7 \%$ of cases which was slightly higher $(3.7 \%)$ that found by Varelas et al [8]. These finding support that small YSD is associated with adverse first triumester outcome and this fact is in agreement with Liao et al [30].

In this study abnormal (irregular) YS was found in $3.8 \%$ of cases. This in contrast of the finding of Chama et al [21] who found 
irregular YS in $18.1 \%$ of their cases. This may be due to a large sample size of their cases 193 cases of them versus 52 cases of ours. Thus; distorted (irregular) shape of YS is an important factor in prediction of poor first trimester outcome.

In this study, there was a statistically high significant difference between embryonic heart rate (EHR) in the miscarriage group (bradycardia) and other groups who continued their pregnancies.

Fetal bradycardia is a sign of impending fetal death reflecting the forth coming collapse of the cardiovascular system. It may be also due to underlying chromosomal abnormality which was associated with fetal bradycardia Liao et al [30].

In the present study embryonic heart rate (EHR) was $98.3 \pm 10.7 \mathrm{bpm}$ in the miscarriage group. This was with agreement of [31], who concluded in his study that a heart rate lower than 100 pbm in early first trimester 6-18 weeks will indicate a poor prognosis irrespective of gestational age.

A significant decrease of EHR was observed in pregnancies that resulted in miscarriage when compared to the ones that continued beyond the first trimester. Such a decrease was found in the majority of previous studies Stefos et al [18] and

Qasim et al [32]. This is in agreement of our findings. However, some researchers have failed to prove this hypothesis. This may be they studied different population (threatened miscarriage) [33].

This study was one of few which simultaneously evaluate yolk sac diameter and embryonic heart rate during the first trimester. The result of this study showed that abnormal or abscent YSD and embryonic braducardia was associated with poor prognosis of first trimester outcome.

The limitation of this study was a small number of the cases and difficulty of follow up the cases; which may be due to no dedicated early pregnancy assessment clinic. So, we recommend establishment of this clinic.

\section{CONCLUSION}

Abnormal yolk sac diameter, in the form of small, enlarged, absent or irregular yolk sac, and embryonic bradycardia are associated with poor pregnancy outcome independent of maternal risk factors such as age, body mass index or parity.

\section{RECOMMENDATIONS}

Yolk sac diameter and embryonic heart rate can be a useful guide in everyday clinical practice, especially if gestational age is taken into account.

In cases with poor ultrasonographic prognostic factors (absence of YS, smaller, bigger or irregular YS and embryonic bradycardia), we should not prematurely reassure the couple, but arrange a repeat ultrasound scan.

Declaration of interest

The authors report no conflicts of interest. The authors alone are responsible for the content and writing of the paper.

Funding information None declared

Fig s1-3: are shown in the online supplement.

\section{REFERENCES}

1) Cunningham F G, Leveno KJ, Bloom sl. Williams Obstetrics, $23^{\text {rd }}$ edition, McGraw-Hill companies 2010; (9): 215-234.

2) Stampone $\mathbf{C}$, Nictora $M$, Muttinelli $C$ and Cosmi EV Transvaginal sonography of the yolk sac in normal and abnormal pregnancy. $\mathbf{J}$ Clin Ultrasound 1996; (24): 3-9.

3) Oh JS, Wright G, Coulam CB. Gestational sac diameter in very early pregnancy as a predictor of fetal outcome. Ultrasound Obstet Gynecol; 20: 267-269lin Ultrasound 2002; (24): 3-9.

4) Mara E, Foster GS. Spontaneous regression of a yolk sac associated with embryonic death. J Ultrasound Med 2000; (19): 655-656.

5) Chama CM, Marupa JY, Obed JY. The value of the secondary yolk sac in predicting pregnancy outcome. J Obstet Gynaecol 2005; (25): 245-247.

6) Martinez JM, Comas C, Ojuel J, Borrell A, Puerto B, Firtuny A et al. Fetal heart patterns in pregnancies with chromosomal disorders or subsequent fetal loss. Obstet Gynecol 1996; (87): 118-121.

7)Cho FN, Kan YY, Chen SN, Yang TL, Hsu FH. Very large yolk sac and bicomuate uterus in a live birth. J Clin Med Assoc 2005; 68 (11): 535-537. 
8) Varelas FK, Prapas NM, Liang RI, Prapas IM and Makedos GA et al. Yolk sac size and embryonic heart rate as prognostic factors of first trimester pregnancy outcome. EJOG 2008; 138: 10-13

9) Tan S, Tangal NG, Kanat PM, Ozean AS, Keskin HL and Akgunduz G et al. Abnormal sonographic appearances of the yolk sac: which can be associated with adverse perinatal outcome? Med Ultrasson 2014; 16(1): 15-20.

10) Shetty AS, Hegde D, Shetty BSK, Padubidri JR et al; Yolk sac abnormalities- Is it a reliable indicator of abortions? A prospective study in the population residing in rural setup of Mangaluru, Karnataka, India. J Pharm Biomed Sci 2015; 05 (05): 380-384.

11) Wong SF, Chan KT and Ho LC et alFetal bradycardia in the first trimester an unusual presentation of atrial extrasystoles. Prenatal Diagnosis 2014; 22(11): 976-978.

12) Makikallio KP and Jouppila JR Humanfetal cardiac function during the first trimester of pregnancy, Heart 2005; 91-(3):334-338.

13) Adija P, Selvi $\mathbf{C}$, Rai L, Hebbar $\mathbf{S}$ et alEvaluation of yolk sac diameter and embryonic heart rate as prognostic factor of gestational outcome in early singleton pregnancies. Scholars Journal of Applied Medical Sciences (SJAMS) 2015; 3 (2A): 543-550.

14) Jauniaux E, Jurkovic D, Henriet Y, Rodesch $\mathbf{F}$, Hustin J et alDevelopment of the secondary human yolk sac: correlation of sonographic and anatomic features. Hum Reprod 1991; (6):11601166

15) Cepni I, Bese T, Ocal P, Budac E, Idil M and Aksu MF et al. Significance of yolk sac measurements with vaginal sonography in the first trimester in the prediction of pregnancy outcome. Acta Obstet Gynecol Scand 1997; (76): 969-972.

16) Varelas FK, Prapas NM, Liang RI, Prapas IM and Makedos GA Yolk sac size and embryonic heart rate as prognostic factors of first trimester pregnancy outcome. EJOG; 138: 10-13.stet Gynecol Scand 2008; (76): 969972.

17) Benson CB and Doubilet PM. Slow embryonic heart rate in early first trimester: indicator of poor pregnancy outcome. Radiology 1994; (192): 343-344.

18) Stefos TI, Lolis DE, Sotiriadis AJ and Ziakas GV et al. Embryonic heart rate in early pregnancy. J Clin Ultrasound 1998; (26): 33-6.

19) Merchiers EH, Dhont M, De Sutter PA, Beghin CA, Vandekerckhove DA et al. Predictive value of early embryonic cardiac activity for pregnancy outcome. Am J Obstet Gynecol 1991; (165):11-14

20) Fu-Nan CHO, San-Nung CHEN, MingHong TAI, Tsung-Lung YANGl. The quality and size of yolk sac in early pregnancy loss. Australian and New Zealand Journal of Obstetrics and Gynaecology 2006; (46): 413.

21) Chama CM, Marupa JY, Obed JY. The value of the secondary yolk sac in predicting pregnancy outcome. J Obstet Gynaecol 2005; (25): 245-7.

22) Moradan S, Forouzeshjfar MF . Are abnormal yolk sac characteristics important factors in abortion rate? International Journal of Fertility and Sterility 2012; 6 (2): 127-130.

23) Srivastava G, Nagwani M, Pasricha N, Tewari V, Siddiqui MS, Sthapak Eti. International Journal of Anatomy and Reserch 2016;4 (1): 2052-2057.

24) Xie YJ, Chen SJ. Prediction of pregnancy outcomes with combined ultrasound scanning of yolk sacs and serum CA 125 determinations in early threatened abortions. Clin Exp Obstet Gynecol 2014; 41 (2): 186-189.

25) Moradan S, Forouzeshjfar MF. Are abnormal yolk sac characteristics important factors in abortion rate? International Journal of Fertility and Sterility 2012; 6 (2): 127-130

26) Shetty AS, Hegde D, Shetty BSK, Padubidri JR. Yolk sac abnormalities- Is it a reliable indicator of abortions? A prospective study in the population residing in rural setup of Mangaluru, Karnataka, India. J Pharm Biomed Sci 2015; 05 (05): 380-384.

27) Kucuk T, Duru NK, Yenen MC, Dede M, Ergun A and Baser I. Yolk sac size and shape as predictors of poor pregnancy outcome. $\mathbf{J}$ Perinat Med 1999; (27): 316-320.

28) Malinowski W. Yolk sacs in twin pregnancy. Ginekol Pol 2000; 71 (8): 815-818.

29) Josel L, Nanditha Abdul Latheef. Sonographic evaluation of yolk sac. International Journal of Scientific \& Engineering Research 2015; 6 (5): 11-15.

30) Liao AW, Snijders R and Geerts L. Fetal heart rate in chromosomally abnormal fetuses. Ultrasound Obstet Gynecol 2000; (16):610.

31) Ozgur Oztekin. First trimester ultrasound: current approaches and practical pitfalls 2009.

32) Qasim SM, Sachder R, Trias A, Senkowski J, Kemmann E. The predictive value of firsttrimester embryonic heart rates in infertility patients. Obstet Gynecol 1997; (89): 934-936.

33) Tannirandorn Y, Sanmgsawang S, Manotaya S, Uerpairojkit B, Samrit-Pradit P, Charoenvidhya D et al. Fetal loss in 
threatened abortion after embryonic/fetal heart activity. Int J Gynecol Obstet 2003; (81): 263266.

34) Valenti O, Di Prima FA, Renda E, Faraci M, Hyseni E, De Domenico $R$ et al. Fetal cardiac function during the first trimester of pregnancy, Journal of Prenatal Medicine 2011; (3): 59.

To Cite This Article: Lebda I, El-Fawal F, El-samak A and Abo Elwan $\mathrm{H}^{*}$. Prognostic Factors of Ultrasonography of Yolk Sac Size and Embryonic Heart Rate in First Trimester Pregnancy Outcome.ZUMJ 2019;25(6);801-808.DOi:10.21608/zumj.2019.11089.11440. 